\title{
RESULTS OF TUBERCULIN TESTS IN MONKEYS AT THE PHILADELPHIA ZOOLOGICAL GARDENS*
}

\author{
C. Y. WHITE, M.D., AND HERBERT FOX, M.D. \\ PHILADELPHIA \\ INTRODUCTION
}

We have not thought it necessary to review the general literature on the subject of injections of tuberculin for diagnostic purposes. Much has been written on this subject in regard to both human beings and domestic animals. We have, however, been able to find comparativeily little on the use of this valuable test applied to wild animals. The opportunity has presented itself to us to follow out the test in the monkeys of the Zoological Gardens of Philadelphia while we were serving in the capacity of pathologists. We present in the following paper the result of our observations on tuberculin as a diagnostic agent in these animals.

The use of this test was started in 1905 , and has been continued to the present. It has been noted in Philadelphia that the average life of a common monkey on exhibition varied between eighteen and twentyone months. It has been found on examination that the great majority of these animals died of tuberculosis. What is true in Philadelphia is probably true in zoological gardens in other parts of the world. This high mortality from tuberculosis led us to adopt some measures to prevent the admission of infected animals and to isolate those already diseased. To accomplish this end the value of the tuberculin test was tried. We began this testing on the stock of monkeys then on exhibition, but very soon found that these were in the advanced stage of tuberculosis and our results were far from satisfactory. It was decided by the officers of the Zoological Society that the infected stock should be destroyed, the monkey house thoroughly cleaned and disinfected, and that thenceforth only those monkeys should be placed on exhibition which failed to react to injections of tuberculin. All incoming monkeys were therefore placed in quarantine in the laboratory and carefully studied as to their general condition. Our observations were directed toward the state of gastrointestinal tract, nervousness, thirst, coughing, and the temperature.

*From the Laboratory of Comparative Pathology of the Zoological Society of Philadelphia. 
We encountered, as might have been expected, many difficulties in the early part of this work, chief of these being the determination of the normal temperature of the monkeys. A thorough study of the normal temperature was our first task, because at that time we had no experience or literary reference to guide us.

The obtaining of the normal daily temperature of the monkeys at a definite time each day was a step in the right direction, but, as will be seen later on, we soon found that even with this daily temperature very much more was to be sought. We found that the temperature of the monkeys varied with the time of day, and to a certain extent with the different species; and, furthermore, that external conditions, such as room temperature, excitation, etc., had an appreciable effect on the record. A further study of this variation showed that the monkeys' temperature fell during the night, while the highest daily temperature was in the neighborhood of 2 to $3 \mathrm{p}$. $\mathrm{m}$. In other words, the normal monkey's temperature reached the highest point between 2 and $3 \mathrm{p}$. m., with a gradual fall to its lowest level, which was about 2 or 3 a. m., after which it again rose to the afternoon height.

It was also ascertained that the normal high temperature of a healthy monkey was higher by three or four degrees than that of a normal human being. This average of temperature varied with the species of monkey under observation, but was usually in the neighborhood of 101 and 102 F. at the highest point; the lowest point in these cases was about three degrees lower, and produced, as will be seen in the charts, definite curves, the lower levels of which we have designated as the "night drop." In order to obtain the daily curve of temperature it was found necessary to make records every four hours. By doing this the normal temperature of a healthy monkey showed an uniform curve which reached its highest point at about $3 \mathrm{p}$. m. and the lowest level at about 3 a. $\mathrm{m}$. Extensive chartings of individual monkeys and the comparison of the temperature of several monkeys showed the uniform curves. The temperature was taken at $\%, 11$ and 3 because the high and low points were at $3 \mathrm{p}$. m. and $3 \mathrm{a}$. m. respectively. It was later found that monkeys of a nervous temperament, those easily excited and those which failed to become accustomed to the taking of temperature, showed variations in the daily curves which could be explained only by the nervous state of these animals.

DETAILS OF THE PRESENT SYSTEM

The monkeys are now received in the quarantine room of the laboratory building. The attendant who has charge of them has had many 
years' experience with monkeys and is familiar with their habits. He takes a very lively interest in helping to take the temperatures and in the application of the test. The animals are allowed to remain quiet in cages for some days before observations are started. Preparatory to the injection of tuberculin daily temperatures are taken at $3 \mathrm{p}$. m., the hour at which the highest temperature point is reached. These daily records are continued until the temperature is seen to maintain an almost even course for about ten days. We have arbitrarily adopted $1^{\circ} \mathrm{F}$. as the limit of variation during the observations previous to the injections. If this variation be in the form of a saw-tooth curve the monkey is allowed to rest for an indefinite time until the temperature becomes regular.

The initial record is usually high, owing, no doubt, to the handling incident to the initiation of the test. After the first few doses the records are lower and usually follow a steadier course. The monkeys are usually removed from their cages with covered hands if they be small and tame, while the larger ones are caught in a net. The great majority of the monkeys readily become accustomed to this daily routine, so that by the time they are ready for the actual test little or no excitement is present. The records are made from rectal temperature in all our work. No time is lost after taking the animal from its cage in obtaining the record, so that the excitement may have as little effect as possible. The thermometer, well greased with petrolatum, is inserted three inches along the anterior wall of the rectum and exposed for three minutes. If the temperature record vary several points from the previous daily record, or if there be any doubt of its correctness, it is retaken.

The normal height for a monkey's temperature can not be stated with exactness compared with that of the human being. The temperature of those normal monkeys which have been killed without evidence of tuberculosis will not allow a definite statement as to the normal temperature of monkeys, as a whole, or of the different species. The daily temperature per rectum at $3 \mathrm{p}$. m. is generally between 101 and $102 \mathrm{~F}$. Some monkeys have passed the test and still live which had an even temperature as high as $104 \mathrm{~F}$. The height per se does not seem indicative of the condition of the monkey unless it be quite high or low, such as $105+$ or $99 \mathrm{~F}$. These extremes are, however, usually combined with irregularity before and after the injection. Starting at the high point, 3 p. m., the temperature begins with 101 to $102 \mathrm{~F}$. and gradually declines, at $7 \mathrm{p}$. m. registering 0.4 to $1 \mathrm{~F}$. lower. At $11 \mathrm{p} . \mathrm{m}$. a similar further fall is seen. The low point is reached about 3 a. m., after which a gradual rise occurs following in reverse order the same general 
course as the fall during the preceding twelve hours, again reaching the high point at three in the afternoon. The average of this fall in the monkeys tested at this laboratory is $3.5 \mathrm{~F}$. In a healthy monkey it may be as low as $1.8 \mathrm{~F}$., or as great as $7 \mathrm{~F}$. (See Chart 1, black ape No. 9, I 6, which shows a healthy normal four-hour temperature.) The temperature of monkeys is elevated by excitement. This is well shown by Simpson and Galbraith, ${ }^{1}$ who studied the temperature of normal monkeys over long periods and the effects of various forms of excitement. They found that the temperature was increased in direct proportion to the degree of excitement. This must be taken into consideration when observing monkeys which do not become accustomed to the excitement incident to taking the temperature. In such cases the temperature must be taken over long periods in order to obtain a definite course of the curves. Occasionally the course of the curves is so irregular that definite conclusions cannot be drawn. Such monkeys are condemned.

\section{TUBERCULIN TEST}

Preparatory to the test the monkey is observed as above described. It has been the practice to make the injection in the forenoon to see what rise may follow at the high point on the same day. Small monkeys such as the average common macaque, will receive 1 to $2 \mathrm{mg}$. Small capucins get 0.75 to $1.5 \mathrm{mg}$; an anubis baboon, or long-armed baboon, may receive as high as $3 \mathrm{mg}$. This dose is rarely exceeded. It will be seen that the dosage is higher than that usually given to human beings, but considerably lower than that given to cattle. This dose was purposely made large because in our early work we found that such doses readily caused tuberculous animals to die, while it had no effect on healthy animals. The injection is given under the loose skin of the flank. We have never seen any local reaction at the site of inoculation. The temperature is then taken every four hours $(3,7,11,3,7,11)$ for forty-eight hours. In the case of a normal monkey the course of the temperature curve follows exactly that described above and illustrated by Chart 1. In some normal monkeys a slight variation may be noted in the length of the night drop immediately following the tuberculin injection. It is frequently, but not always, 0.4 to $0.6 \mathrm{~F}$. lower during the first than during the second night. This is, however, not constant or marked enough to allow any diagnostic value to be put upon it. In the case of tuberculous animals the most common occurrence is a rise of temperature within twelve hours after injection. The daily curve may

1. Simpson and Galbraitl: Tr. Roy. Soc. Edinburgh, 1906, xiv, Part I, p. 75 . 
be entirely destroyed, the temperature following instead a course higher than indicated by the previous daily $3 \mathrm{p} . \mathrm{m}$. record. The destruction of the daily curve, with an elevated temperature, is the most significant: indication of a positive test-i.e., tuberculosis. Failure to make the normal night drop in a few cases has taught us to be always doubtful of the condition, for we have found that a subsequent test will usually give a positive reaction. In some few cases and for reasons unknown to us the characteristic rise indicative of a positive reaction, does not take place until some time within the second twenty-four hours. In these latter cases we generally speak of the reaction as a "delayed reaction." This delayed reaction has the usual characteristics of a positive test. Here a case may be cited in point. White-throated Cebus No. 27 (D. 7 ; See Chart 2) showed the temperature series taken many times from September, 1905, to January, 1906. The course was very irregu-

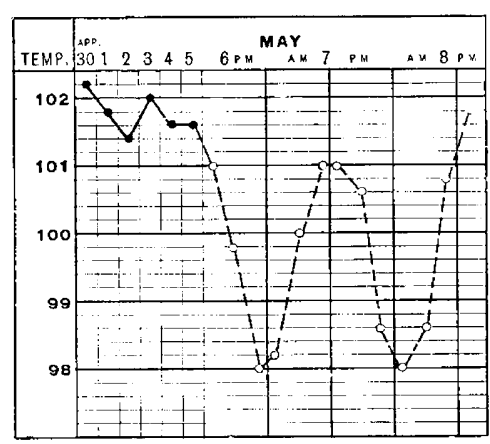

Chart 1 (I 6).-Black ape No. 9; injected May 6, 1907; passed May 10, 1907; died Sept. 27, 1907. Autopsy showed no tuberculosis.

lar at first and he was not injected until Jan. 28, 1906. A rise of $1 \mathrm{~F}$. followed the injection, but the rest of the curve was about normal. $\mathrm{He}$ was held over and retested March 23, at which test the curves did not seem low enough. His temperature remained irregular during the summer while he was under observation. In November, 1906, he was tested again after a more regular period. The first day did not fall very low, but followed a regular progression until the 11 o'clock a. m. temperature on the second day, which was the high point instead of $3 \mathrm{p} . \mathrm{m}$. There was a very irregular, shallow curve during the next twenty-four hours and at $3 \mathrm{p}$. $\mathrm{m}$. on the third day the record was $0.6 \mathrm{~F}$. higher than any previous one in this course. At autopsy the only sign of tuberculosis was in the right bronchial lymph gland, where two small progressive tubercles were found. This well illustrates the desirability of taking: 

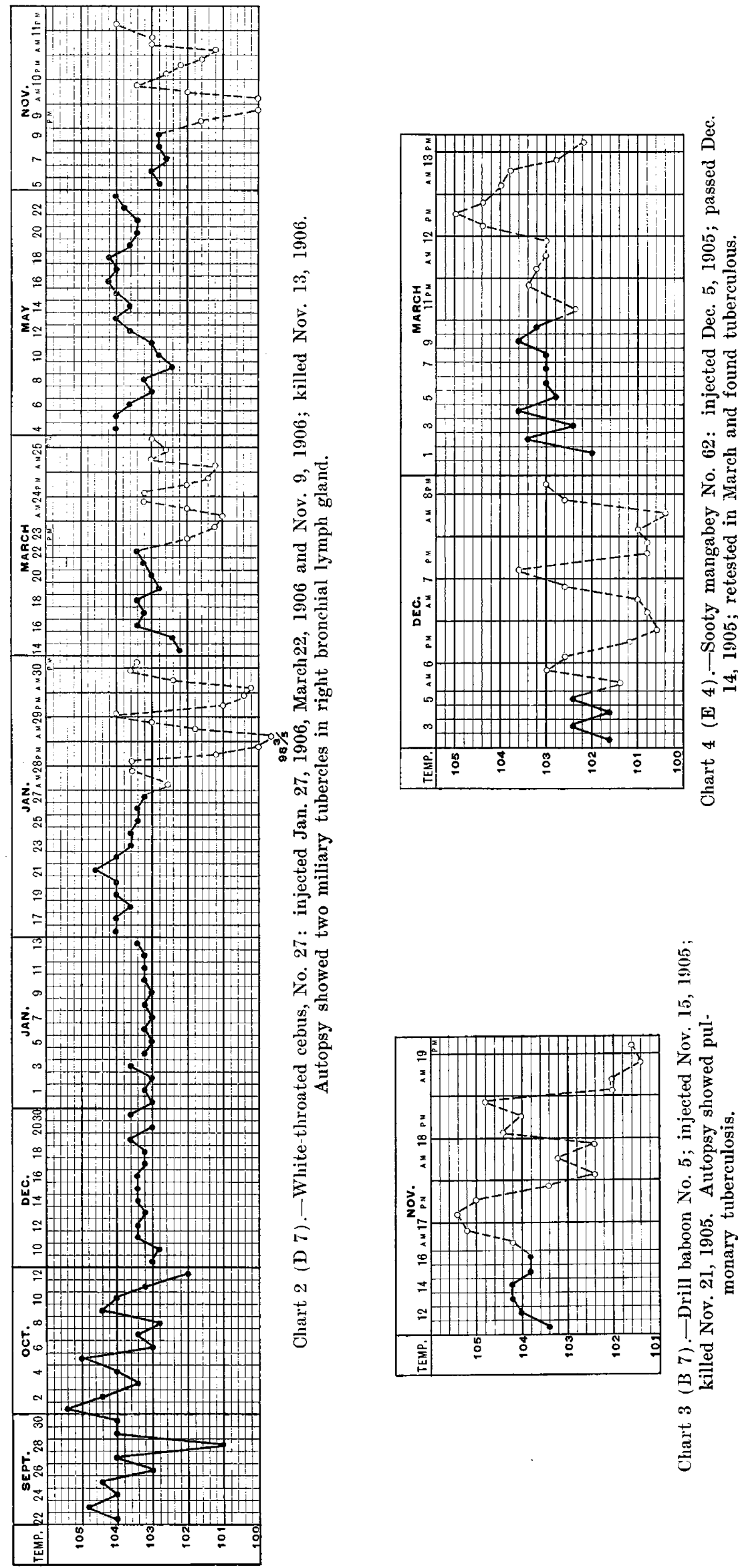

Downloaded From: http://archinte.jamanetwork.com/ by a University of California - San Diego User on 06/09/2015 
the temperature two days after the injection, and how minute a lesion will cause a reaction. Good charts of tuberculous monkeys after the test are seen in drill baboon 5 (B 7) and sooty mangabey 62 (E 4), Charts 3 and 4.

The temperature in advanced cases of tuberculosis may fall below the registering point of the thermometer shortly following the test. 'This is well illustrated by lesser white-nosed monkeys $\mathrm{C} 2$, Chart 5 , and pig-tailed macaque No. 69 (A 8), Chart 6. In both of these cases the animal died. We have occasionally noted an unusually deep night drop immediately following the injection in monkeys which were subsequently found on autopsy to be healthy. The temperature of these monkeys showed an approximately normal rhythm, without a rise above the 3 p. m. high point.

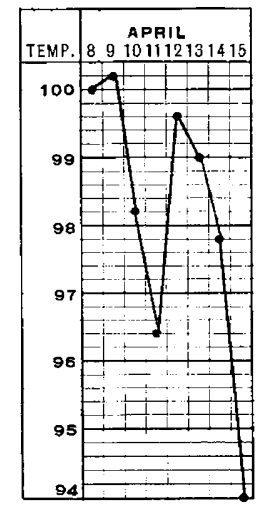

Chart 5.-Lesser white-nosed monkey: died April 16, 1905, after injection of $5 \mathrm{mg}$. of tuberculin.

The relation of the degree of reaction to the extent or severity of the lesions is a very uncertain one and our experience allows no conclusions on this score with the exception noted above concerning very advanced cases of tuberculosis. The case just cited (D \%, Chart 2) shows a positive reaction and only a minute trace of infection. A black ape gave a most pronounced reaction and had only a few pin-head-sized tubercles in the liver and spleen, while sooty mangabey No.62 (E 4, Chart 4), drill No. 5 (B $\%$, Chart 3), gave no more marked reactions and showed advanced lesions at autopsy. Perhaps the rule is for the temperature to fall in the most active and widespread cases.

The number of monkeys received at the gardens and tested during the time these observations have been made is as follows: One hundred and twenty-eight monkeys received; passed, 81 ; condemned or died at 
or near the time of the first injection and not on exhibition, 4\%. It will be seen from this that only 63.3 per cent. of the monkeys received actually passed the tuberculin test. Of the 81 monkeys which were passed 79 were sent to the monkey house; 5 died there as the result of tuberculosis. They lived one, three, eight and sixteen months. Five others were returned, retested or killed and found tuberculous. The rest remain apparently normal to date. No monkey passed since February, 1906 , has as yet developed any sign of tuberculosis. In reviewing the charts of the monkeys dead of tuberculosis and of those associated with them in the cages it is possible to suspect the source of infection of at least several of these animals. The total deaths from tuberculosis among monkeys which had been in the monkey house since the test was begun is ten, of which eight may with reasonable certainty be traced to two infections from cases which occurred early in the tests, of which the temperature charts would not have been passed had we had the experi-

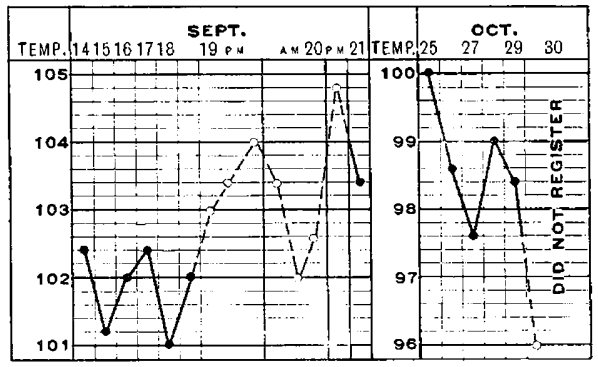

Chart 6 (A 8).-Pigtailed macaque No. 69; injected Sept. 19, 1905, and Oet. 29, 1005; died Nov. 1, 1905. Autopsy showed general tuberculosis.

ence later gained. From March 1, 190\%, to March 1, 1908, there were two deaths, and the last death from tuberculosis was on Oct. 1\%, $190 \%$.

The monkeys which passed the test and showed tuberculosis after being returned from the monkey house for any reason are as follows:

Sooty mangabey, No. 62, passed on forty-eight-hour temperature; returned and found tuberculous after being on exhibition three months.

Sooty mangabey, No. 63, passed on forty-eight-hour temperature; on exhibition three months; injected, gave a questionable reaction; gave a positive reaction eight months after return. The reaction on which it was passed was questionable.

Sooty mangabey, No. 60, passed on forty-eight-hour temperature which was questionable; returned in three months; eight months after return positive reaction, tuberculosis.

Grivet, No. 9, passed on questionable forty-eight-hour temperature; returned in three months; positive reaction; killed, tuberculosis. 
Black ape, No. 7 (I 2), passed on twenty-four-hour temperature; returned in three months; gave questionable reaction; a regular daily temperature for a long time; gave a positive reaction three months after return; tuberculosis.

Monkeys dying from tuberculosis in the monkey house were as follows:

Drill, No. 6, passed on good forty-eight-hour temperature, died in monkey house eight months afterward of tuberculosis.

Anubis baboon, No. 34, passed on good forty-eight-hour temperature; on exhibition sixteen months; returned and killed; tubereulosis.

Common macaque, No. 205, passed on twenty-four-hour temperature; on exhibition three months; returned; irregular; forty-eight-hour temperature; tuberculosis.

Sooty mangabey, No. 59, passed on good twenty-four-hour temperature, then on forty-eight-hour temperature; after twenty months on exhibition died of tuberculosis. (Traceable to five days' exposure to sooty mangabeys Nos. 60,62 and 63.)

Grivet monkey, No. 8, passed on twenty-four-hour temperature; one month on exhibition; returned, tuberculosis.

The following is the list of monkeys which were tested early in our work. Their temperature was taken after the injection for only twentyfour hours. Of these fourteen monkeys six died of tuberculosis, some of which were included in the above lists. Seven of the fourteen were retested on the basis of a forty-eight hour temperature after injection, and six of these were negative to the test, while the remaining one gave a positive reaction. This determined for us the necessity of taking the temperature for forty-eight hours at least following the injection.

PASSED ON TWENTY-FOUR-HOUR TEMPERATURE

C-3, Aug. 15, 1905, remaining

A-3, Aug. 15, 1905, remaining

$B-4$, Aug. 31, 1905, remaining

$\mathrm{B}-5$, Aug. 31, 1905, remaining
Retested at monkey House, forty-eight-hour temperature, Passed.

Have been at the monkey house three years one month since passing twenty-four hour test.

DIED, NOT TUBERCƯLOUS

B-3, passed on twenty-four-hour temperature; retested at monkey house, forty-eight-hour temperature and passed; on exhibition two years, five months; died, not tuberculous.

I-1, passed on twenty-four-hour temperature; retested at monkey house, forty-eight-hour temperature, repassed; on exhibition one year, ten months; died, not tuberculous.

$\mathrm{I}-4$, passed on twenty-four-hour temperature; on exhibition two months; died, not tuberculous.

A-26, passed on twenty-four-hour temperature; on exhibition twenty-one days; died, not tuberculous.

DHED, TLBERCLOC's

B-2, tested, twenty-four-hour temperature; died, general tuberculosis.

A-2, tested, twenty-four-hour temperature; died, general tuberculosis.

$A-4$, passed, twenty-four-hour temperature; died, tuberculous. 
A-6, tested, twenty-four-hour temperature; died, general tuberculosis.

C-7, tested, twenty-four-hour temperature; died, general tuberculosis.

$I-2$, passed, twenty-four-hour temperature; retested at monkey house; returned on forty-eight-hour temperature; again tested (forty-eight-hour) ; killed; general tuberculosis.

\section{CONCLUSIONS}

1. Tuberculosis is a disease which causes a considerable mortality among monkeys. The habits of the animals, moreover, facilitate the transmission of the disease when many are together on exhibition.

2. The primary object of this work was to protect the healthy monkeys by separation of the infected ones. It was therefore diagnostic work, and the use of tuberculin for therapeutic purposes was not tried.

3. It is not possible to trace the source of infection; whether from human beings or from the lower animals. From the number of monkeys that were condemned on the first test it is evident that a large percentage are affected while in the hands of the dealers.

4. To insure the protection afforded by the test, the exhibition house must be freed of infected animals, disinfected, and only non-tuberculous monkeys admitted. The monkeys on exhibition should be retested at least once a year and doubtful animals removed from the cages.

5. To apply the test scientifically a thorough familiarity with the normal temperature of the monkeys is necessary.

6. The normal temperature of the monkey is higher than that of the human being by 4 to $5 \mathrm{~F}$. at its highest point. It follows a regular curve during the twenty-four hours, with the high point at $3 \mathrm{p} . \mathrm{m}$. in: the neighborhood of 101 to $102 \mathrm{~F}$; its lowest level, about $99 \mathrm{~F}$., at 3 a. $\mathrm{m}$.

\%. An injection of tuberculin into a non-infected monkey will not disturb the rhythm of the normal temperature.

8. An injection of tuberculin into an infected monkey will cause a definite rise in temperature, a destruction of the daily curve, the performance of a course higher than the daily temperature at the previous high point, or any or all of these.

9. By the test we have been able to detect tuberculosis in $37 \mathrm{per}$ cent. of 128 monkeys tested.

10. No monkey which has passed the test-i.e., given a negative reaction since February, 1906 - has shown as yet any evidence of tuberculosis, although some have died from other causes and others have been killed upon suspicion.

11. Ten of the 79 monkeys which were passed were subsequently found tuberculous, either in the exhibition cages or after having been 
returned to the laboratory for any reason. These infections are probably traceable to two monkeys which passed the test because of a misinterpretation of their temperature after injection during our early work.

12. By careful consideration of the temperature; by rigid adherence to hygienic measures in quarantine, and by observation of the individual peculiarities of the animals, the tuberculin test will prove an effcient means of separating infected monkeys and preserving exhibition collections.

These investigations here reported were made possible by the broadminded interest and co-operation of the directors of the Zoological Society of Philadelphia; and we wish to acknowledge with thanks the assistance of Dr. Arthur Erwin Brown, secretary of the society, in our work.

Since the writing of this article six months have elapsed and the statements herein still hold good. It has now been eighteen months since the last monkey on exhibition died of tuberculosis. This monkey was exposed to a tuberculous monkey which passed the early test, before the delayed reactions or the night drop in the temperatures were thoroughly understood. No monkey has been returned for a retest from the exhibition cages or having died of other causes has been found tuberculous of the monlieys tested since February, 1906, or in the past thirtyeight months.

The results of the above methods of testing monkeys and of placing healthy monkeys under good hygienic surroundings for exhibition purposes demonstrates the great value of such tests as the tuberculin test and further gives a very practical lesson in preventive medicine when ideal conditions are offered.

1808 Diamond Street-4443 spruce Street. 